\title{
On-scalp magnetoencephalography for childhood
}

\section{epilepsies}

Odile Feys ${ }^{1,2}$, Pierre Corvilain ${ }^{2}$, Alec Aeby $^{3}$, Claudine Sculier $^{4}$, Florence Christiaens $^{4}$, Niall Holmes $^{5}$, Matthew Brookes 5 , Serge Goldman ${ }^{2,6}$, Vincent Wens ${ }^{2,6}$, Xavier De Tiège ${ }^{2,6}$

\section{Abstract}

Magnetoencephalography (MEG) is an established method to investigate epilepsy. Current MEG systems house hundreds of cryogenic sensors in a rigid, one-size-fits-all helmet, which results in several limitations, particularly in children. On-scalp MEG based on opticallypumped magnetometers (OPMs) may alleviate these limitations.

We report on five children $(5-11$ years old) with self-limited focal $(n=3)$ or structural $(n=2)$ epilepsy who underwent cryogenic (102 magnetometers) and on-scalp (32 OPMs) MEG. We compared the two modalities for the detection and localization of interictal epileptiform discharges (IEDs).

We identified IEDs in all children with comparable sensor topographies for both MEG devices. IED amplitudes were 2.3-4.8 times higher with on-scalp MEG and signal-to-noise ratio (SNR) was also $27-60 \%$ higher with on-scalp MEG in all but one patient with large head movement artifacts. The neural source of averaged IEDs was located at about $5 \mathrm{~mm}(\mathrm{n}=3)$ or higher $(8.3$ $\mathrm{mm}, \mathrm{n}=1 ; 15.6 \mathrm{~mm}, \mathrm{n}=1$ ) between on-scalp and cryogenic MEG.

Despite limited number of sensors and scalp coverage, on-scalp MEG detects IEDs in epileptic children with higher SNR than cryogenic MEG. This technology, which is in constant development, should become a reference in the diagnostic workup of epilepsy and replace cryogenic MEG in the near future. 
medRxiv preprint doi: https://doi.org/10.1101/2021.09.06.21262839; this version posted September 12, 2021. The copyright holder for this preprint (which was not certified by peer review) is the author/funder, who has granted medRxiv a license to display the preprint in

\section{Author affiliations:}

${ }^{1}$ Department of Neurology, CUB Hôpital Erasme, Université libre de Bruxelles (ULB), Brussels, Belgium.

${ }^{2}$ Laboratoire de Cartographie fonctionnelle du Cerveau (LCFC), ULB Neuroscience Institute (UNI), Université libre de Bruxelles (ULB), Brussels, Belgium.

${ }^{3}$ Department of Pediatric Neurology, Hôpital Universitaire des Enfants Reine Fabiola (HUDERF), Université libre de Bruxelles (ULB), Brussels, Belgium.

${ }^{4}$ Department of Pediatric Neurology, CUB Hôpital Erasme, Université libre de Bruxelles (ULB), Brussels, Belgium.

${ }^{5}$ Sir Peter Mansfield Imaging Centre, School of Physics and Astronomy, University of Nottingham, University Park, Nottingham NG7 2RD, United Kingdom.

${ }^{6}$ Clinics of Functional Neuroimaging, Service of Nuclear Medicine, CUB Hôpital Erasme, Université libre de Bruxelles (ULB), Brussels, Belgium.

Corresponding author: Dr Odile Feys, Laboratoire de Cartographie fonctionnelle du Cerveau (LCFC), ULB Neuroscience Institute (UNI), Université libre de Bruxelles (ULB), 808 Lennik Street, Brussels, Belgium. Telephone : +3225555588. E-mail : odile.feys@ulb.be

Running title: On-scalp MEG for epilepsy

Keywords: Epilepsy, Childhood, Magnetoencephalography

\section{Abbreviations:}

EZ

Epileptogenic zone

IED

$$
\text { Interictal epileptiform discharge }
$$


medRxiv preprint doi: https://doi.org/10.1101/2021.09.06.21262839; this version posted September 12,2021 . The copyright holder for this preprint (which was not certified by peer review) is the author/funder, who has granted medRxiv a license to display the preprint in It is made available under a CC-BY-NC-ND 4.0 International license .

MEG Magnetoencephalography

MSR Magnetic shielded room

OPM Optically-pumped magnetometer

OPM-MEG Optically-pumped magnetometer based magnetoencephalography

SL-ECTS Self-limited epilepsy with centro-temporal spikes

SNR Signal-to-noise ratio

SQUID Superconducting quantum interference device

SWI Spike-wave index

\section{Introduction}

Magnetoencephalography (MEG) has proven its clinical added value for the non-invasive localization of the irritative zone in patients with refractory focal epilepsy, ${ }^{1,2}$ especially for epilepsy originating from outside the temporal lobe that are common in children. ${ }^{3}$ MEG improves patients' surgical management by (i) detecting irritative zones not captured by conventional EEG, (ii) contributing to subtle brain lesion detection, or (iii) improving intracranial EEG planning/surgical resection accuracy. ${ }^{2-5}$

Current cryogenic MEG systems house hundreds of superconducting quantum interference devices (SQUIDs) in a rigid, one-size-fits-all helmet. ${ }^{6}$ SQUIDs are the main limitation of cryogenic MEG (for details, see ${ }^{6}$ ). Because of their need for cryogenic cooling, a thermally insulating gap is required between the scalp and sensor, meaning the brain-to-sensor distance is about $2-5 \mathrm{~cm}$ in adults who fit the system well, and even larger in subjects with small heads such as children. Small head size increases the brain-to-sensor signal attenuation (as magnetic fields decrease with the square of the distance) and lead to larger head movements within adultsized helmets when children struggle to keep still. 
medRxiv preprint doi: https://doi.org/10.1101/2021.09.06.21262839; this version posted September $12,2021$. The copyright holder for this preprint (which was not certified by peer review) is the author/funder, who has granted medRxiv a license to display the preprint in

It is made available under a CC-BY-NC-ND 4.0 International license.

Optically-pumped magnetometers (OPMs) are novel cryogen-free magnetic field sensors. They can be placed directly on the scalp to record neuromagnetic signals with an adequate level of noise, even during movements. ${ }^{6}$ Consequently, OPM arrays can adapt to any head shape or size, and record human brain activity in natural conditions. ${ }^{6}$ On-scalp OPM-based MEG (OPMMEG) should substantially improve signal-to-noise ratio (SNR) and spatial resolution, especially in children. ${ }^{6}$

OPM-MEG recording (15 OPMs, bespoke 3D-printed scanner cast housing the OPMs) has been described in one adult patient with refractory focal epilepsy. ${ }^{7}$ OPM-MEG was able to detect and localize the source of interictal epileptic discharges (IEDs) but a direct comparison with SQUID-MEG was missing.

Here, we study OPM-MEG in the routine clinical use by comparing IED recordings using 32 OPMs fixed on comfortable and flexible EEG-like caps with recordings from SQUID-MEG in five children with extratemporal focal epilepsy.

\section{Materials and Methods}

\section{Patients}

Between April and June 2021, we collected five children with focal epilepsy (4F/1M; median age, 9.4 years; range, 5-11 years; Table 1) who met the inclusion criteria. Three patients had self-limited genetic focal epilepsy, while the two others had refractory focal epilepsy of unknown cause (one with focal hypometabolism on PET with [18F]-fluorodeoxyglucose concordant with the presumed epileptogenic zone (EZ) but without detectable lesion on structural brain 3 Tesla MRI, one who was not seizure-free after a resected right temporal dysembryoplastic neuroepithelial tumor with a distant presumed EZ; Patients 2 and 5 in Table 1). Three of the five patients had epileptic encephalopathy. ${ }^{8}$ Inclusion criteria were (i) selflimited epilepsy with centro-temporal spikes (SL-ECTS) or lesional/non-lesional refractory 
medRxiv preprint doi: https://doi.org/10.1101/2021.09.06.21262839; this version posted September $12,2021$. The copyright holder for this preprint (which was not certified by peer review) is the author/funder, who has granted medRxiv a license to display the preprint in

It is made available under a CC-BY-NC-ND 4.0 International license .

focal epilepsy, (ii) frequent unifocal IEDs on a previous clinical EEG, and (iii) ability to remain relatively still for at least 15 min of MEG recordings.

This study was approved by the Ethics Committee of the CUB Hôpital Erasme (Reference: P2019/426, B406201941248). Parents and children gave written informed consent prior to their inclusion.

-Place Table 1 about here-

\section{Data acquisition}

OPM-MEG was performed using 32 zero-field magnetometers (Gen-2.0, QuSpin Inc, Colorado, USA; single-axis mode, gain $2.7 \mathrm{~V} / \mathrm{nT}$ ) whose signal was fed to a digital acquisition unit (National Instruments, Texas, USA; sampling rate $1200 \mathrm{~Hz}$, no band-pass filter). To maximize patients' collaboration and comfort during prolonged recordings, we adapted the concept of flexible EEG-like cap previously described ${ }^{9}, 10$ for OPM-MEG recordings (Figure 1). We 3D printed plastic sensor mounts (64 per EEG cap, Figure 1, Left) that were sewn on conventional flexible EEG caps (EasyCap, Herrsching, Germany; 2 sizes to adapt to children's head circumference) according to the 10-10 EEG system to rigidly fix OPMs on the scalp. This design prevented the insertion of any material between the scalp and the cap that represented potential source(s) of discomfort or pain. ${ }^{9}$ The mounts covered about $40 \%$ of the inferior part of the OPMs and had vertical openings (Figure 1, Middle) to allow dissipation of OPM-related heat. Each mount was also equipped with one hollow at each corner of the mount base (Figure 1, Middle) to allow quick (about $10 \mathrm{~min}$ ) and precise digitization of OPM position on children's scalp using an electromagnetic tracker (Fastrak, Polhemus, Colchester, VT, USA). This flexible cap was easy and quick (1-2min) to install on children's head. Three small marks were also drawn on the children's forehead and EEG cap (one right, one middle, one left) using a skin 
medRxiv preprint doi: https://doi.org/10.1101/2021.09.06.21262839; this version posted September $12,2021$. The copyright holder for this preprint (which was not certified by peer review) is the author/funder, who has granted medRxiv a license to display the preprint in It is made available under a CC-BY-NC-ND 4.0 International license.

pencil to check that the cap did not move relative to children's head during acquisition. Sensors were placed around the presumed EZ as determined by previous EEG. Recordings of 15-30 min (according to age) took place inside a compact magnetically shielded room (MSR) optimized for OPM recordings (OPM-compact MuRoom, Magnetic Shielded Limited, Kent, UK), with a background magnetic field of less than $15 \mathrm{nT}$ after deGaussing. Children comfortably sat at the MSR center, watched a movie, with no constraint on head position or movement. Of note, no further field compensation ${ }^{6}$ was applied here. Sensor locations were obtained outside the MSR after the recording and careful removal of OPMs by digitizing the four base points of each mount housing an OPM (Figure 1, Middle) and at least 300 points (face and scalp) relative to anatomical fiducials. This digitization procedure took about $10 \mathrm{~min}$ in each child.

SQUID-MEG (Figure 1, Left) was recorded in similar conditions using a commercial 306channel, whole-scalp neuromagnetometer placed in a light-weight MSR (Triux and Maxshield, MEGIN, Helsinki, Finland; 204 planar gradiometers, 102 magnetometers; sampling rate $1000 \mathrm{~Hz}$, band-pass filter $0.1-300 \mathrm{~Hz}) .{ }^{11}$ Head movements were tracked by four position indicator coils. These coils and 300 face/scalp points were digitized relative to anatomical fiducials using the same electromagnetic tracker.

OPM-MEG was done before SQUID-MEG in all children.

Each patient also underwent a 3D T1-weighted brain MRI, either during their clinical assessment (1.5 T Intera, Philips, The Netherlands) or after the MEG (3T Signa PET-MR, GE Healthcare, Illinoi, USA).

— Place Figure 1 about here - 
medRxiv preprint doi: https://doi.org/10.1101/2021.09.06.21262839; this version posted September $12,2021$. The copyright holder for this preprint (which was not certified by peer review) is the author/funder, who has granted medRxiv a license to display the preprint in

It is made available under a CC-BY-NC-ND 4.0 International license .

\section{Data preprocessing}

Both MEG data were denoised using distinct spatial filters, i.e., principal components analysis for OPMs (3 first components associated with slow, large-amplitude drifts and movement artefacts were removed) and signal space separation with movement correction (Maxfilter, MEGIN) for SQUIDs. ${ }^{12}$ Signals were then band-pass filtered at 3-40 Hz for IED detection. For comparability with OPM-MEG, SQUID-MEG was restricted to its 102 magnetometers.

For source reconstruction, the MRI was manually co-registered to OPM-MEG and SQUIDMEG separately using their respective digitalization (MRIlab, MEGIN). Forward models were computed for both modalities using the one-layer boundary element method (MNE-C ${ }^{13}$ ) based on MRI tissue segmentation (Freesurfer ${ }^{14}$ ). For OPM-MEG, sensor locations and orientations were estimated from the digitalization.

\section{Data analysis}

IEDs were visually identified in MEG signals by trained neurologists (O.F., X.D.T.). A spikewave index (SWI) was computed for each data set (i.e., OPM- and SQUID-MEG) and patient as in ${ }^{15}$. Data were epoched from -300 to $300 \mathrm{~ms}$ after each spike event, baseline corrected (from $-100 \mathrm{~ms}$ to $-50 \mathrm{~ms}$ ) and finally averaged. The neural source at the peak of averaged spikes were localized using an home-made implementation of dynamic statistical parametric mapping ${ }^{16}$ (noise covariance estimated from baseline data, regularization from the global $\mathrm{SNR}^{17}$ ).

Peak amplitude and SNR of IEDs were estimated at each spike event for the sensor showing maximum averaged spike amplitude and compared across modalities using two-sided unpaired $t$ tests. This allowed comparing two unequal sets (OPM- vs. SQUID-MEG) of IEDs for each patient. Finally, the distance between the reconstructed neural sources and the closest OPM or 
medRxiv preprint doi: https://doi.org/10.1101/2021.09.06.21262839; this version posted September $12,2021$. The copyright holder for this preprint (which was not certified by peer review) is the author/funder, who has granted medRxiv a license to display the preprint in It is made available under a CC-BY-NC-ND 4.0 International license .

SQUID sensor was estimated to assess how much closer OPM sensors were from the brain compared with SQUIDs.

\section{Data availability}

Data are available upon reasonable request to the corresponding author and after approval of institutional (i.e., CUB Hôpital Erasme \& Université libre de Bruxelles) authorities.

\section{Results}

Table 1 summarizes the results of all children. Figure 2 illustrates the data obtained in patients 3 and 5.

Both types of MEG recordings were well tolerated by the children and resulted in good data quality in all but one child (Patient 4), who exhibited episodic large movement artefacts in OPM-MEG data. No misalignment of the EEG cap relative to children's forehead was noticed based on the three marks.

Unifocal and monomorphic IEDs were found in all children with SWI ranging from 2 to $89 \%$. At the sensor level, IEDs had comparable sensor topographies for both types of MEG and were consistent with previous clinical EEG. IEDs amplitude was systematically higher (from 2.3 to 4.8 times higher) with OPM-MEG compared with SQUID-MEG, with high statistical significance (negligibly small $p$ value). Their SNR was also significantly higher (from 27 to $60 \%$ higher) with OPM-MEG in all but one (Patient 4).

At the source level, the distance of the neural source of the averaged IEDs peak ranged from $4.2 \mathrm{~mm}$ to $15.6 \mathrm{~mm}$ between OPM- and SQUID-MEG reconstructed sources. The mean distance between the reconstructed neural source and the closest sensor was $29.4 \mathrm{~mm}$ for OPMMEG and $57.6 \mathrm{~mm}$ for SQUID-MEG. 
medRxiv preprint doi: https://doi.org/10.1101/2021.09.06.21262839; this version posted September 12,2021 . The copyright holder for this preprint (which was not certified by peer review) is the author/funder, who has granted medRxiv a license to display the preprint in It is made available under a CC-BY-NC-ND 4.0 International license .

- Place Figure 2 about here-

\section{Discussion}

This case series demonstrates that, compared with SQUID-MEG, multichannel OPM-MEG (i) is well tolerated in five children aged 5-11 years with focal epilepsy, (ii) accurately detects IEDs, (iii) provides significantly higher IED amplitude in all children, (iv) provides significantly higher IED SNR in all but one child, and (v) locates similar or close neural sources of IEDs. This was achieved despite a smaller number of sensors (32 vs. 102) and consequent limited scalp coverage.

To fit routine clinical use in epilepsy, we adapted the flexible EEG cap ${ }^{9,10}$ for on-scalp OPM recordings to maximize patients' collaboration and comfort. This light and flexible cap design was operator- and child-friendly, and contributed to the excellent tolerance of OPM-MEG by the epileptic children, already used to undergoing EEG investigations. It also has the advantage of placing sensors at the scalp surface, which is difficult to reach with rigid helmets. One possible disadvantage is that any movement of the OPM relative to the scalp during the recording will lead to artifacts and inaccuracies in the source reconstruction. The mount design also facilitated the OPM localization procedure that took about $10 \mathrm{~min}$ in each child, which was well tolerated and reasonable. In the near future, the adaptation of optical co-registration techniques ${ }^{8}$ will certainly allow to speed up and increase the accuracy of this localization.

IEDs were detected in all patients with comparable SWI between OPM- and SQUID-MEG. IED peak amplitudes were 2.3 to 4.8 times higher with OPM- than with SQUID-MEG. This merely reflects the reduced ( $\sim 3 \mathrm{~cm}$ on average) brain-to-sensor distance afforded using OPMs. ${ }^{6}$ Still, OPM signals were generally noisier than SQUID signals, although intrinsic sensor noise is similar ${ }^{18}$, because children were free to move and consequent OPM movements created signal artefacts commensurate to the background magnetic environment. By opposition, SQUIDs are 
medRxiv preprint doi: https://doi.org/10.1101/2021.09.06.21262839; this version posted September 12,2021 . The copyright holder for this preprint (which was not certified by peer review) is the author/funder, who has granted medRxiv a license to display the preprint in It is made available under a CC-BY-NC-ND 4.0 International license .

fixed and subjected to efficient software denoising. ${ }^{12}$ Importantly, despite these disadvantages, IED peak SNR remained significantly higher with OPM-MEG in four children and similar than SQUID-MEG in the other with large movements (Patient 4), which suggest that our EEG cap setup is adequate for pediatric recordings of IEDs. Movement-related artefacts in OPM signals could be reduced substantially with extra hardware solutions such as field nulling coils ${ }^{6}$ (which would likely reduce background fields from $\sim 15 \mathrm{nT}$ to $<1 \mathrm{nT}$, and consequently reduce movement artifacts by a similar factor) and the development of OPM denoising algorithms. ${ }^{19}$, ${ }^{20}$ Therefore, the quality of OPM-MEG recordings in epileptic children will continue to improve in the coming years to fully overpass SQUID-MEG.

Differences in the location of IED reconstructed neural sources based on OPM- and SQUIDMEG signals were in the range of SQUID-MEG spatial resolution (i.e., about $5 \mathrm{~mm} ; 3$ patients) or higher (2 patients). The latter could be related to different IED neural generators (nonsimultaneous recordings), differences in the number and spatial coverage of sensors, inaccuracies in the digitization procedure, or the higher SNR of OPM signals. Still, OPM-MEG based on 32 sensors placed around the presumed EZ can identify similar IED neural generators than SQUID-MEG. An increase in the number of sensors for OPM-MEG and the development of triaxial OPM sensors ${ }^{20}$ should position OPM-MEG as the future reference for clinical MEG investigations.

This study was limited by the difficulty to compare the sensitivity of IED detection of both modalities intrinsically associated with non-simultaneous recordings, the absence of a reference standard (e.g., intracranial recording, resection cavity) to compare the spatial precision of source reconstructions (see ${ }^{21}$ for a discussion on this issue), the limited number and spatial coverage of OPMs, and the small number of children investigated. Still, it provides unprecedented evidence supporting the clinical added value of OPM-MEG compared with SQUID-MEG. OPM-MEG have major advantages of in the field of epilepsy. Compared to 
medRxiv preprint doi: https://doi.org/10.1101/2021.09.06.21262839; this version posted September $12,2021$. The copyright holder for this preprint (which was not certified by peer review) is the author/funder, who has granted medRxiv a license to display the preprint in

It is made available under a CC-BY-NC-ND 4.0 International license .

EEG, they are easy to use with no need of electrolyte gel or electrode gluing on the scalp. Compared to SQUID-MEG, there is no need of head position indicator coils, they are movement-friendly, which opens the possibility of routine ictal MEG and prolonged videoMEG recordings, and their cost is reduced. This nascent technology has therefore all the potential to supplant SQUID-MEG in the clinical management of epileptic patients. As a future method of reference, it is expected to even replace scalp EEG in certain circumstances.

\section{Funding}

Odile Feys is supported by a research grant from the Fonds pour la Formation à la Recherche dans l'Industrie et l'Agriculture (FRIA, Fonds de la Recherche Scientifique (FRS-FNRS), Brussels, Belgium). Pierre Corvilain is supported by a research grant from the Fonds Erasme (Research Convention “Alzheimer”, Brussels, Belgium). Xavier De Tiège is Postdoctorate Clinical Master Specialist at the FRS-FNRS.

This study has been supported by the Fonds Erasme (Research Conventions "Les Voies du Savoir" \& "Projet de recherche clinique à des techniques médicales émergentes 2020") and the FRS-FNRS (Equipment credit : U.N013.21F).

The OPM- and SQUID-MEG projects at the CUB Hôpital Erasme are financially supported by the Fonds Erasme.

\section{Competing interests}

Niall Holmes (Scientific Advisor) and Matthew Brookes (Chairman) are involved in CERCA Magnetics Limited (https://www.cercamagnetics.com/). The other authors have no conflict of interest. 
medRxiv preprint doi: https://doi.org/10.1101/2021.09.06.21262839; this version posted September $12,2021$. The copyright holder for this preprint (which was not certified by peer review) is the author/funder, who has granted medRxiv a license to display the preprint in It is made available under a CC-BY-NC-ND 4.0 International license .

\section{References}

1. Burgess RC. MEG for Greater Sensitivity and More Precise Localization in Epilepsy. Neuroimaging Clin N Am. 2020;30(2):145-58.

2. Rampp S, Stefan H, Wu X, Kaltenhauser M, Maess B, Schmitt FC, et al. Magnetoencephalography for epileptic focus localization in a series of 1000 cases. Brain. 2019;142(10):3059-71.

3. De Tiege X, Carrette E, Legros B, Vonck K, Op de Beeck M, Bourguignon M, et al. Clinical added value of magnetic source imaging in the presurgical evaluation of refractory focal epilepsy. J Neurol Neurosurg Psychiatry. 2012;83(4):417-23.

4. Burgess RC. Clinical MEG passes another milestone. Brain. 2019;142(10):2897-900.

5. Murakami H, Wang ZI, Marashly A, Krishnan B, Prayson RA, Kakisaka Y, et al. Correlating magnetoencephalography to stereo-electroencephalography in patients undergoing epilepsy surgery. Brain. 2016;139(11):2935-47.

6. Boto E, Holmes N, Leggett J, Roberts G, Shah V, Meyer SS, et al. Moving magnetoencephalography towards real-world applications with a wearable system. Nature. 2018;555(7698):657-61.

7. Vivekananda U, Mellor S, Tierney TM, Holmes N, Boto E, Leggett J, et al. Optically pumped magnetoencephalography in epilepsy. Ann Clin Transl Neurol. 2020;7(3):397-401.

8. Scheffer IE, Berkovic S, Capovilla G, Connolly MB, French J, Guilhoto L, et al. ILAE classification of the epilepsies: Position paper of the ILAE Commission for Classification and Terminology. Epilepsia. 2017;58(4):512-21. 
medRxiv preprint doi: https://doi.org/10.1101/2021.09.06.21262839; this version posted September $12,2021$. The copyright holder for this preprint (which was not certified by peer review) is the author/funder, who has granted medRxiv a license to display the preprint in It is made available under a CC-BY-NC-ND 4.0 International license.

9. Hill RM, Boto E, Rea M, Holmes N, Leggett J, Coles LA, et al. Multi-channel wholehead OPM-MEG: Helmet design and a comparison with a conventional system. Neuroimage. 2020;219:116995.

10. Boto E, Hill RM, Rea M, Holmes N, Seedat ZA, Leggett J, et al. Measuring functional connectivity with wearable MEG. Neuroimage. 2021;230:117815.

11. De Tiege X, Op de Beeck M, Funke M, Legros B, Parkkonen L, Goldman S, et al. Recording epileptic activity with MEG in a light-weight magnetic shield. Epilepsy Res. $2008 ; 82(2-3): 227-31$.

12. Taulu S, Simola J. Spatiotemporal signal space separation method for rejecting nearby interference in MEG measurements. Phys Med Biol. 2006;51(7):1759-68.

13. Gramfort A, Luessi M, Larson E, Engemann DA, Strohmeier D, Brodbeck C, et al. MEG and EEG data analysis with MNE-Python. Front Neurosci. 2013;7:267.

14. Fischl B. FreeSurfer. Neuroimage. 2012;62(2):774-81.

15. Aeby A, Santalucia R, Van Hecke A, Nebbioso A, Vermeiren J, Deconinck N, et al. A qualitative awake EEG score for the diagnosis of continuous spike and waves during sleep (CSWS) syndrome in self-limited focal epilepsy (SFE): A case-control study. Seizure. 2021;84:34-9.

16. Dale AM, Sereno MI. Improved Localizadon of Cortical Activity by Combining EEG and MEG with MRI Cortical Surface Reconstruction: A Linear Approach. J Cogn Neurosci. $1993 ; 5(2): 162-76$.

17. Wens V, Marty B, Mary A, Bourguignon M, Op de Beeck M, Goldman S, et al. A geometric correction scheme for spatial leakage effects in MEG/EEG seed-based functional connectivity mapping. Hum Brain Mapp. 2015;36(11):4604-21.

18. Shah VK, Wakai RT. A compact, high performance atomic magnetometer for biomedical applications. Phys Med Biol. 2013;58(22):8153-61. 
medRxiv preprint doi: https://doi.org/10.1101/2021.09.06.21262839; this version posted September $12,2021$. The copyright holder for this preprint (which was not certified by peer review) is the author/funder, who has granted medRxiv a license to display the preprint in It is made available under a CC-BY-NC-ND 4.0 International license .

19. Rea M, Holmes N, Hill RM, Boto E, Leggett J, Edwards LJ, et al. Precision magnetic field modelling and control for wearable magnetoencephalography. Neuroimage. 2021;241:118401.

20. Mellor SJ, Tierney T, O'Neill G, Alexander N, Seymour R, Holmes N, et al. Magnetic Field Mapping and Correction for Moving OP-MEG. IEEE Trans Biomed Eng. 2021;PP.

21. Knowlton RC, Elgavish RA, Limdi N, Bartolucci A, Ojha B, Blount J, et al. Functional imaging: I. Relative predictive value of intracranial electroencephalography. Ann Neurol. 2008;64(1):25-34.

\section{Figure legends}

Figure 1. OPM- and SQUID-based MEG. Left. Illustration of the MSR dedicated to OPMs. Middle left. Illustration of the flexible EEG-like cap set-up used in this study for OPM-MEG recordings. Middle right. Illustration of the 3D printed plastic mount sewn on the EEG cap and housing one OPM oriented radially. Mounts covered about $40 \%$ of the inferior part of the OPMs and had vertical openings to allow dissipation of OPM-related heat. Each mount was also equipped with one hollow at each corner of the mount base (small rounds with hollow) to allow quick and precise digitization of OPM position on children's scalp. Right. Illustration of the SQUID-MEG used in this study.

Figure 2. SQUID- and OPM-MEG data. (A) Patient 3. Top, Left. Sample of the background brain activity and of some IEDs recorded with SQUID- and OPM-MEG. Signals from a selected group of magnetometers were superimposed. Top, Right. Averaged IED signals along with the magnetic field topography (sensor array viewed from top, arbitrary scale) at the spike peak 
medRxiv preprint doi: https://doi.org/10.1101/2021.09.06.21262839; this version posted September 12, 2021. The copyright holder for this preprint (which was not certified by peer review) is the author/funder, who has granted medRxiv a license to display the preprint in It is made available under a CC-BY-NC-ND 4.0 International license.

(indicated by purple vertical line). Bottom. Neural source reconstructions obtained at the averaged IED peak and displayed on parasagittal (Left; left hemisphere), coronal (Middle) and two axial (Right) brain MRI slices. The distance between locations of maximum source activity for OPM- and SQUID-MEG was $15.6 \mathrm{~mm}$. (B). Patient 5. Legend is similar to A. Bottom. Axial brain MRI slice (Left) illustrating the resection cavity of the right temporal dysembryoplastic neuroepithelial tumor. Source reconstructions with OPM- and SQUID-MEG are displayed on parasagittal (Left; right hemisphere), coronal (Middle), and axial (Right) slices. The localization difference was $5.4 \mathrm{~mm}$. 
medRxiv preprint doi: https://doi.org/10.1101/2021.09.06.21262839; this version posted September 12, 2021. The copyright holder for this preprint (which was not certified by peer review) is the author/funder, who has granted medRxiv a license to display the preprint in

It is made available under a CC-BY-NC-ND 4.0 International license.

Table 1: Epileptic children's clinical characteristics and results of MEG investigations

\begin{tabular}{|c|c|c|c|c|c|c|c|c|c|c|c|}
\hline Patient & $\begin{array}{l}\text { Age (y), age (y) at } \\
\text { seizure onset, type } \\
\text { of epilepsy }\end{array}$ & IED & $\begin{array}{l}\text { Duration } \\
\text { of MEG } \\
\text { recording } \\
\text { (min) }\end{array}$ & $\begin{array}{c}\text { SWI } \\
\text { OPM/SQUID }\end{array}$ & $\begin{array}{c}\text { Distance (mm) } \\
\text { between sources } \\
\text { and OPM/SQUID } \\
\text { sensor }\end{array}$ & $\begin{array}{l}\text { Distance (mm) } \\
\text { between sources } \\
\text { reconstructed } \\
\text { with OPM- and } \\
\text { SQUID-MEG }\end{array}$ & $\begin{array}{l}\text { SQUID- } \\
\text { MEG IED } \\
\text { amplitude, } \\
\text { (mean+/- } \\
\text { SD, pT) }\end{array}$ & $\begin{array}{l}\text { OPM-MEG } \\
\text { IED } \\
\text { amplitude } \\
\text { (mean+/- } \\
\text { SD, pT) }\end{array}$ & $\begin{array}{l}\text { SQUID- } \\
\text { MEG } \\
\text { IED } \\
\text { SNR } \\
\text { (mean+/ } \\
\text {-SD) }\end{array}$ & $\begin{array}{l}\text { OPM- } \\
\text { MEG } \\
\text { IED } \\
\text { SNR } \\
\text { (mean+/ } \\
\text {-SD) }\end{array}$ & $\begin{array}{c}\text { OPM- vs. } \\
\text { SQUID- } \\
\text { MEG } \\
\text { IED SNR } \\
p \text { value }\end{array}$ \\
\hline 1 & $\begin{array}{c}11-15,6-10, \text { SL- } \\
\text { ECTS }\end{array}$ & L CT & 30 & $6 \% / 5 \%$ & $31.9 / 67.1$ & 4.4 & $2.95+/-0.08$ & $9.93+/-0.19$ & $\begin{array}{c}13.2+/- \\
0.82\end{array}$ & $\begin{array}{c}16.7+/- \\
0.86\end{array}$ & 0.0039 \\
\hline 2 & $\begin{array}{c}\text { 11-15, 1-5, non- } \\
\text { lesional }\end{array}$ & L F & 30 & $3 \% / 2 \%$ & $33.2 / 64.2$ & 8.3 & $0.66+/-0.06$ & $3.16+/-0.21$ & $\begin{array}{l}8.0+/- \\
0.96\end{array}$ & $\begin{array}{c}12.8+/- \\
1.60\end{array}$ & 0.0089 \\
\hline 3 & $1-5,0$, SL-ECTS & $\mathrm{L} \mathrm{CT}$ & 18 & $55 \% / 47 \%$ & $24.5 / 48.7$ & 15.6 & $3.10+/-0.09$ & $7.21+/-0.17$ & $\begin{array}{l}9.3+/- \\
0.40\end{array}$ & $\begin{array}{c}11.8+/- \\
0.51\end{array}$ & 0.0005 \\
\hline 4 & $\begin{array}{c}\text { 6-10, 6-10, SL- } \\
\text { ECTS }\end{array}$ & L CT & 30 & $5 \% / 5 \%$ & $30.9 / 60.9$ & 4.2 & $1.48+/-0.06$ & $3.78+/-0.21$ & $\begin{array}{c}11.3+/- \\
0.89\end{array}$ & $\begin{array}{c}11.4+/- \\
1.15\end{array}$ & 0.9276 \\
\hline 5 & $\begin{array}{c}\text { 11-15, 6-10, } \\
\text { lesional }\end{array}$ & $\mathrm{R} \mathrm{CT}$ & 30 & $89 \% / 85 \%$ & $26.1 / 56.8$ & 5.4 & $1.84+/-0.07$ & $7.66+/-0.12$ & $\begin{array}{c}11.1+/- \\
1.22\end{array}$ & $\begin{array}{c}15.0+/- \\
0.74\end{array}$ & 0.0079 \\
\hline
\end{tabular}

Y, years; SL-ECTS, self-limited epilepsy with centro-temporal spikes; IED, interictal epileptiform discharge; L, left; R, right; CT, centrotemporal; F, frontal; MEG, magnetoencephalography; SWI, spike-wave index; OPM, optically-pumped magnetometer; SQUID, superconducting quantum interference device; OPM-MEG, optically-pumped magnetoencephalography; SD, standard deviation, SNR, signal-to-noise ratio. 
A

Raw data

Averaged data

SQUID $4.5 \mathrm{pt}$.

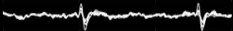

$500 \mathrm{~ms}$

OPM
$9 \mathrm{pI}$

$500 \mathrm{mr}$
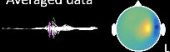

y.
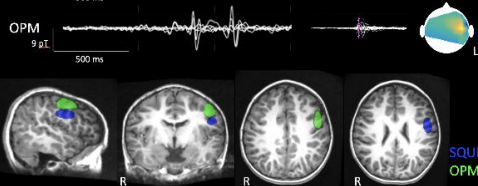

SQLIID

OPM

B

Raw data

Averaged data

SQUID

$1.75 \mathrm{pT}$

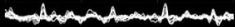
$500 \mathrm{~ms}$

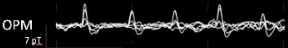

$500 \mathrm{mr}$
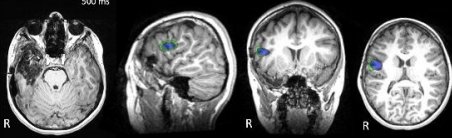

SQUID $\mathrm{OPM}$
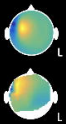


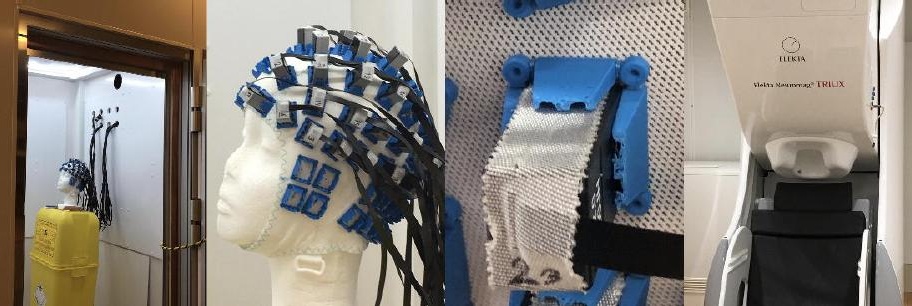

